\title{
Cyclooxygenase in Cancer Prevention and Treatments for Actinic Keratosis
}

\author{
Gareth J. Thomas · Colin A. Morton
}

Received: August 11, 2016

(C) The Author(s) 2017. This article is published with open access at Springerlink.com

\begin{abstract}
Non-steroidal anti-inflammatory drugs (NSAIDs) are a chemically diverse class of drugs that target the cyclooxygenase (COX) pathway and have anti-inflammatory, analgesic, and antipyretic properties. Elevated expression of COX-2 has been associated with tumor progression in skin cancer through multiple mechanisms. We present evidence for a chemoprotective effect of NSAIDs and discuss potential mechanisms of action of COX-2 in cancer. We also discuss the challenges associated with the treatment of actinic keratosis and the factors that should be taken into consideration when selecting a treatment regimen. A range of treatments are reviewed, with an emphasis on combination therapies.
\end{abstract}

Enhanced content To view enhanced content for this article go to http://www.medengine.com/Redeem/ 6C47F0600685C21C.

G. J. Thomas ( $\square)$

Cancer Sciences Unit, Faculty of Medicine, University of Southampton, Southampton, UK e-mail: G.Thomas@soton.ac.uk

C. A. Morton

NHS Forth Valley, Stirling, Scotland, UK
Keywords: Actinic keratosis; Cancer prevention; Cyclooxygenase; Non-steroidal anti-inflammatory drugs; Prognosis; Treatment

\section{INTRODUCTION}

Non-steroidal anti-inflammatory drugs (NSAIDs), a chemically diverse class of drugs with anti-inflammatory, analgesic, and antipyretic properties, target the cyclooxygenase (COX) pathway [1]. Two major isoforms of COX exist: COX-1 and COX-2 [2]. While both catalyze an identical enzymatic reaction, the two are independent and are implicated in distinct physiologic and pathogenic processes, and they differ in their pattern of expression: COX-1 is constitutively expressed in most tissues [3], whereas COX-2 is usually induced by numerous physiologic stimuli [4]. COX-1 and COX-2 are involved in the synthesis of prostaglandins (PGs), catalyzing the conversion of arachidonic acid to PGH2. PGH2 is subsequently converted to a number of eicosanoids, including PGD2, PGE2, PGF2a, PGI2, and thromboxane (TX). Both COX-1 and COX-2 are capable of synthesizing PGs from arachidonic acid. However, it has been shown that PGE2 and PGI2 are mainly derived from the COX-2 pathway [5]. The variety of $\mathrm{PGs}$ produced depends on the downstream enzymatic machinery present in a particular cell type. For 
example, platelets predominantly produce TXA2.

\section{COX-2 AND SKIN CANCER}

Elevated expression of COX-2 occurs in many cancers, where it contributes to tumor progression through multiple mechanisms $[6,7]$. There is strong evidence from epidemiologic studies and animal models that COX-2 is involved in the development and progression of cutaneous squamous cell carcinoma (SCC) and may represent a target for prevention and/or therapy [8-11].

COX-2 expression is upregulated in human and murine SCC, accompanied by a high level of PG synthesis [6]. Genetic and pharmacologic approaches have been used to demonstrate the contribution of COX and PGs to murine skin cancer: COX-2 knockout mice are significantly protected from UV-induced skin cancer compared with wild-type mice [8]. Conversely, transgenic mice overexpressing COX-2 in the epidermis develop many more tumors in response to UV treatment compared with wild-type mice [8]. UV-induced COX-2 expression increases PGE2 production, and overexpression of the PGE2 receptors EP1, 2, and 4 is also associated with increased numbers of UV-induced tumors [12-14]. Selective COX-2 inhibitors have been shown to suppress UV- and carcinogen-induced SCC $[10,11,15]$. For example, application of celecoxib has been shown to reduce UV-associated skin damage in mice and the number and size of new skin tumors [10]. The nonselective NSAIDs naproxen, aspirin, and sulindac have also been found to significantly reduce the number of UV-induced skin tumors [2].

While COX-1 and COX-2 are present in non-melanoma skin cancer in humans [9], COX-2 is the primary UV-responsive COX isoform in human skin. UV radiation is a known stimulus for COX-2 expression in the epidermis, and single doses of UV (1-2 minimal erythema dose) results in a substantial increase in COX-2 expression, with no change in COX-1 expression [16]. While COX-2 is not detectable in normal skin, it is upregulated in SCC and actinic keratosis (AK) [17].

Epidemiologic evidence supports a preventive effect for NSAIDs in the development of SCC. An Australian case-control study on a cohort of 1621 individuals found that people who used NSAIDs twice a week or more for at least a year had a significantly lower incidence of AKs and SCCs than those who did not [18]. A Danish population-based case-control study also found a decreased risk of developing SCC and malignant melanoma in individuals taking NSAIDs, especially with long-term ( $\geq 7$ years) or high-intensity use $(>25 \%$ of prescription coverage during total duration of use) [19]. Although several studies have not found a significant association between NSAIDs and SCC protection [20, 21], a recent meta-analysis of published studies revealed that aspirin and other oral NSAIDs are associated with a significant reduction in the risk of SCC compared with non-use of NSAIDs, and this association is particularly evident among individuals with a history of AK or SCC (Fig. 1). The analysis was not able to determine whether the dose or duration of NSAID administration impacted on SCC prevention [22]. A meta-analysis of topical NSAID treatment of AKs with the COX-2 inhibitor diclofenac in $2.5 \%$ hyaluronic acid found that target lesions were completely resolved in $40 \%$ of cases after a mean 75 days of treatment [23]. There is evidence indicating that diclofenac, which has been approved for the treatment of $\mathrm{AK}$ in the form of diclofenac/hyaluronic acid, acts by inducing cell death. Topic treatment of four SCC cell lines (acting as a model for AK because of a general lack of AK cell lines) with diclofenac/hyaluronic acid was found to induce apoptosis, possibly by sensitizing neoplastic keratinocytes to death ligand-induced apoptosis [24].

\section{THE MECHANISM OF ACTION OF COX-2 IN MALIGNANCY}

The mechanism by which COX-2 promotes SCC development is unclear; however, the 


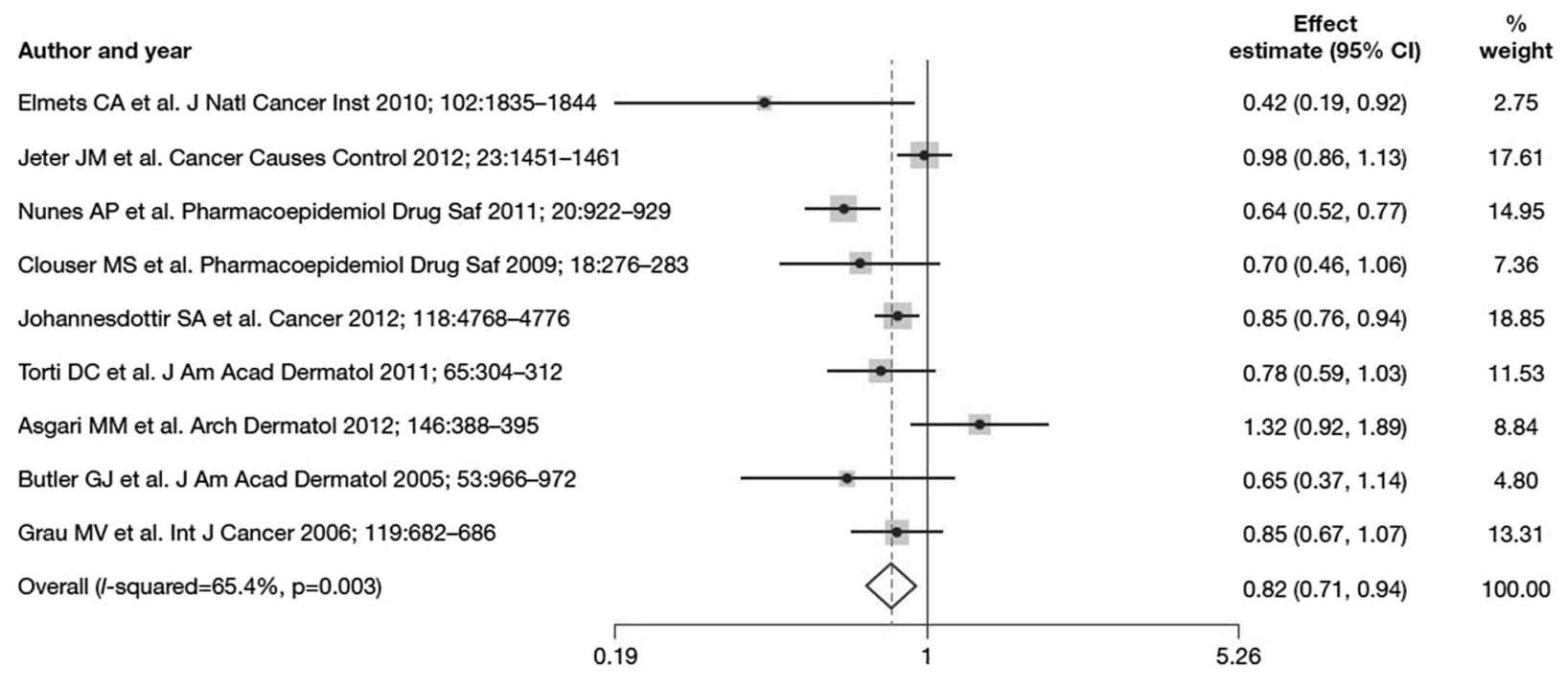

Fig. 1 Forest plot of the association between NSAID (any aspirin or non-aspirin NSAID) use and SCC development [22]. Reprinted from J Invest Dermatol, 135, Muranushi $\mathrm{C}$ et al., Aspirin and nonsteroidal anti-inflammatory drugs can prevent cutaneous squamous cell carcinoma: a

systematic review and meta-analysis, 975-83, Copyright 2015, with permission from Elsevier. CI confidence interval, NSAID non-steroidal anti-inflammatory drug, $S C C$ squamous cell carcinoma

enzyme has been shown to promote several functions associated with malignant transformation and progression. PGE2 stimulates the proliferation of keratinocytes [10], and this effect can be suppressed by NSAIDs, which also act to promote keratinocyte apoptosis. COX-2 expression in SCC has also been shown to correlate with epithelial-to-mesenchymal transition, suggesting that COX-2 may promote cell motility. Consistent with this, COX-2 has been associated with invasion in squamous carcinomas of the head, neck, and esophagus $[25,26]$. While PGE2 is involved in the inflammatory process, paradoxically, it also has an immunosuppressive role [27]. The COX-2/PGE2/EP pathway can suppress activity of dendritic cells, NK cells, and T-lymphocytes and promote tumor immune evasion [28]. Zelenay and colleagues recently demonstrated a synergistic effect between COX inhibitors and immune checkpoint inhibitors in a murine cancer model, suggesting that NSAIDs may have utility as an immunotherapeutic adjunct [29].

\section{When Should Actinic Keratosis be Treated?}

The decision to treat a patient with AK lesions is made on the basis of clinical factors, such as a history of AK lesion persistence, the age of the patient, presence of discomfort, the extent of co-existing photodamage, expected tolerance to the side effects of therapy, and history of skin cancer [30].

Further support for the decision to treat AK lesions comes from the finding that similar genes are differentially expressed in $\mathrm{AK}$ and SCC, confirming that AK is a precursor lesion of SCC [31]. Elucidation of the process by which SCC develops from AK has revealed that the classical progression from AK I to II to III, and subsequently SCC, occurs in a substantial proportion of cases, while the direct progression from AK I to SCC (the so-called differentiated pathway) is also common [32]. (See 'Skin cancer-Epidemiology, Disease Burden, Pathophysiology, Diagnosis and Therapeutic Approaches,' by Zoe Apalla, Dorothée Nashan, Richard Weller, and Xavier Castellsagué, 
published in this Supplement, for examples of AK clinical cases.)

\section{SELECTING THE MOST APPROPRIATE TREATMENT}

There are increasing numbers of treatment options for $\mathrm{AK}$ and, correspondingly, a greater choice for patients. However, the range of available options can be limited by healthcare costs and/or reimbursement complications, in addition to the preferences of the physician (and patient) for procedural, topic, or combination treatment. Consequently, delivering the most appropriate therapy may be a challenge. Given the scope of the current article, we summarize below those treatment options that are applicable to the European market.

Selecting the most appropriate treatment should take into account the clinical presentation of AK: the type, distribution, and location of lesions and whether field or lesional treatment is necessary. Also, data on the efficacy and tolerability of treatments, patient preference, and cost-effectiveness (prescriber preference and price) should be considered. Several evidence-based treatment guidelines are available to assist clinicians in navigating the field, including those from the Primary Care Dermatology Society (Fig. 2).

\section{Physically Destructive Methods}

Lesion- or field-directed treatment options aimed at physically destroying AK lesions include cryotherapy and laser treatment. Cryotherapy is non-specific and uses liquid nitrogen to freeze and promote necrosis of lesions, although both atypical and normal cells are at risk of destruction. It is widely used for small, or a low number of, AK lesions [33-35]. A single application of cryotherapy may be sufficient, or treatment can be repeated several times [35]. Laser (either $\mathrm{CO}_{2}$ or Er:YAG) treatment destroys skin to a controlled depth [34]. It is useful when there is co-existent photodamage or where lesions are recalcitrant, although hypopigmentation may be a problem [36].

\section{Surgical Removal}

Surgical removal of AK lesions involves excision or curettage and is suitable for single, discrete, hyperkeratotic lesions [35]. Surgery is unlikely to be the first line of treatment, unless diagnosis is uncertain [34]. While there are no clinical trials evaluating the efficacy of surgery for AK lesions, it is likely to be effective [34].

\section{Topical Treatments}

A number of topical treatments are available for the treatment of AK lesions. Diclofenac 3\% in hyaluronic acid [37] is administered twice daily for 60-90 days for the treatment of AK lesions in all body areas. Although the mechanism of action of diclofenac in AK is not known, it may be related to the inhibition of the cyclooxygenase pathway leading to reduced PGE2 synthesis. Common side effects include usually mild erythema, crusting, scaling, and pruritus.

5-Fluorouracil 5\% is a chemotherapeutic agent that destroys tumor cells via blocking the methylation reaction of deoxyuridylic acid to thymidylic acid. Treatment is administered once or twice daily for 3-4 weeks, and a normal response is associated with an early and severe inflammatory phase (usually week 2 ), followed by a necrotic phase and then healing. Other common side effects include erythema, crusting, and pigmentation changes [38].

5-Fluorouracil $0.5 \%$ plus $10 \%$ salicylic acid (5-FU/SA) comprises an antimetabolite combined with a keratolytic agent to reduce hyperkeratoses. This is administered once daily for 6-12 weeks for slightly palpable and/or moderately thick hyperkeratotic AK (grade I/II) lesions on the face, forehead, or balding scalp (epidermal thickness must be considered when administering to other sites). Common side effects of 5-FU/SA include erythema, inflammation, irritation, pain, and pruritus [39-41].

Imiquimod 5\%, a Toll-like receptor 7 agonist, disrupts tumor proliferation and induces cytokines with indirect anti-tumor 


\begin{tabular}{|c|c|c|c|c|c|c|}
\hline & \multirow[b]{3}{*}{ Generic name } & \multirow{2}{*}{$\begin{array}{c}\text { Grade I } \\
\text { Single or few lesions, } \\
\text { better felt than seen }\end{array}$} & \multirow{2}{*}{\begin{tabular}{|c|} 
Grade II \\
$\begin{array}{c}\text { Moderately thick lesions, } \\
\text { easily felt \& seen }\end{array}$
\end{tabular}} & \multirow{2}{*}{$\begin{array}{c}\text { Grade III } \\
\begin{array}{c}\text { Thick hyperkeratotic } \\
\text { lesions }\end{array}\end{array}$} & \multicolumn{2}{|c|}{ Field change } \\
\hline & & & & & Small - up to $25 \mathrm{~cm}^{2}$ & Large \\
\hline & & & & \pm & & \\
\hline \multirow{6}{*}{ 쥼 } & 3\% Diclofenac with HA & $\checkmark \checkmark$ & $\checkmark$ & $x$ & $\checkmark \checkmark$ & $\checkmark \checkmark$ \\
\hline & $5 \%$ Fluorouracil $(5-\mathrm{FU})$ & $\checkmark$ & $\checkmark \checkmark$ & $\bar{x}$ & $\checkmark \checkmark$ & $\bar{\checkmark}$ \\
\hline & $5 \%$ Imiquimod & $\checkmark$ & $\bar{s}$ & $x$ & $\bar{\checkmark}$ & $x$ \\
\hline & $0.5 \% 5-\mathrm{FU}+10 \%$ Salicylic acid & $\checkmark \checkmark$ & $\checkmark \checkmark$ & $x$ & $x$ & $x$ \\
\hline & $3.75 \%$ Imiquimod & $\bar{s}$ & 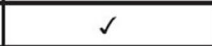 & $\bar{x}$ & $\bar{s}$ & $d s$ \\
\hline & $\begin{array}{l}0.015 \% \text { Ingenol mebutate - face \& scalp } \\
0.05 \% \text { Ingenol mebutate - trunk \& limbs }\end{array}$ & $\checkmark$ & $\checkmark \checkmark$ & $x$ & $\checkmark \checkmark$ & $x$ \\
\hline \multirow{3}{*}{$\begin{array}{l}\frac{\grave{\Phi}}{\Phi} \\
\frac{\Phi}{0}\end{array}$} & Liquid nitrogen & 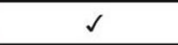 & $\checkmark$ & 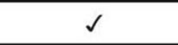 & $x$ & $x$ \\
\hline & Photodynamic therapy & $\checkmark$ & $\checkmark$ & $x$ & $\checkmark$ & $\checkmark$ \\
\hline & Curettage & $\checkmark$ & $\checkmark$ & $\checkmark$ & $x$ & $x$ \\
\hline
\end{tabular}

$\checkmark$ Relative recommendation $\checkmark \checkmark$ Strong recommendation $\quad x$ Not recommended in Primary Care

Fig. 2 Primary Care Dermatology Society treatment guidelines (2014) for actinic keratosis [61]. Reproduced with kind permission from the Primary Care Dermatology

effects. It is applied three times per week for 4 weeks on typic, non-hyperkeratotic, non-hypertrophic AK lesions on the face/scalp; this is done prior to normal sleeping hours and washed off after approximately $8 \mathrm{~h}$. In Europe, this treatment cycle can be repeated after 4 weeks if required [42]. Common side effects include erythema, crusting, and scaling (treatment can be interrupted if intense local inflammatory reactions occur). Flu-like symptoms including headaches, fever, and chills may also be experienced. Imiquimod $3.75 \%$ is applied once daily for 2 weeks for AK lesions on the face/scalp (Europe). This is followed by a 2 -week break without treatment and then a further 2 weeks with treatment [43].

Ingenol mebutate was isolated from Euphorbia peplus and is involved in rapid targeted cell necrosis and an immune response. It is applied on non-hyperkeratotic, non-hypertrophic AK lesions to the trunk/extremities (500 $\mu \mathrm{g}$ gel) once daily for 2 days and to the face/scalp (150 $\mu$ g gel) once daily for 3 days. Erythema, flaking/scaling, and crusting typically occur within 1 day of initiation and peak in intensity up to 1 week following completion of treatment $[44,45]$.
Society. Treatment recommendations of national dermatology societies and associations may differ from those suggested by the Primary Care Dermatology Society

Conventional methyl aminolevulinatephotodynamic therapy (MAL-PDT) is administered to thin or non-hyperkeratotic and non-pigmented $\mathrm{AK}$ lesions on the face/scalp. After topical application of methyl aminolevulinate, porphyrins accumulate intracellularly [including protoporphyrin IX (PpIX) as photoactive, fluorescing compounds]; light activation leads to a photochemical reaction and thereby phototoxicity to the light-exposed target cells. During light exposure, common side effects include burning/stinging pain, whereas post-therapy swelling and erythema are often followed by crusting [46]. Conventional aminolevulinic acid-photodynamic therapy (ALA-PDT), involving the application of 5-aminolevulinic acid, is administered to patients with mild-to-moderate $\mathrm{AK}$ lesions on the face/scalp (Olsen grade I-II; refer to Fig. 2) [47-49]. For conventional ALA-PDT, common side effects are similar to those observed with conventional MAL-PDT. Daylight MAL-PDT $[46,50,51]$ may be used to treat patients with mild-to-moderate AK lesions and is suitable for most weather conditions (avoiding rainy days) above $10^{\circ} \mathrm{C}$. Pain is a common side effect but minimal compared with standard PDT. 


\section{Combination Therapy}

Field therapies have often been combined (or used sequentially) with each other or with lesion-targeted therapies in an effort to improve results by taking advantage of the synergy of the individual mechanisms of action [35]. There is increasing interest in the use of combination or sequential therapy in an effort to improve outcomes.

In a small study of patients with multiple grade $\mathrm{I} / \mathrm{II} \mathrm{AK}$ lesions (including recurrence), diclofenac in hyaluronic acid was administered twice daily for 12 weeks, followed by a 2-week treatment-free interval, and then 5-fluorouracil (5-FU) + salicylic acid once daily for up to 6 weeks, as required. Complete clinical and histologic clearance occurred in $83.3 \%$ of 12 patients [52].

The combination of diclofenac/hyaluronic acid therapy with cryotherapy, using different freeze times and order of therapy, resulted in higher lesion clearance rates than single-agent therapy [53-55].

An enhanced clinical effect was observed when AK lesions were pre-treated with diclofenac/hyaluronic acid or 5-FU before photodynamic therapy (PDT), sequential PDT and imiquimod, with patients having fewer lesions at follow-up compared with those who were not pre-treated [56-58]. The combination of PDT with other treatments, such as diclofenac/hyaluronic acid, 5-FU, imiquimod, or ingenol mebutate, appears to improve outcomes with PDT [59]. However, most of the studies have included small numbers of patients, with clinical evaluation only, and no histologic confirmation of results. Further studies with larger numbers of patients and longer follow-up are needed to evaluate these combinations more fully [59].

\section{ECONOMIC CONSIDERATIONS}

In the outpatient setting, $\mathrm{AK}$ is among the most commonly treated skin conditions $[33,60]$. As $\mathrm{AK}$ is a disease with increasing incidence, which may evolve to SCC, the willingness by payers to cover the cost of AK therapy has increased. As with all treatments, the National Health Service and payers will consider clinical data, unmet needs, the burden of illness, and the cost-effectiveness and budgetary impact of potential therapies.

More research is needed on epidemiologic data, evidence-based standards, delineating cost drivers in immunocompetent and immunocompromised patients, and on health outcomes.

This article is based on previously conducted studies and does not involve any new studies of human or animal subjects performed by any of the authors.

\section{ACKNOWLEDGEMENTS}

Sponsorship and article processing charges for this supplement were funded by Almirall S.A. This article is based on presentations from the 9th Skin Academy Symposium, 9-10 April 2016, Barcelona, Spain, sponsored by Almirall S.A. All named authors meet the International Committee of Medical Journal Editors (ICMJE) criteria for authorship for this manuscript, take responsibility for the integrity of the work as a whole, and have given final approval to the version to be published. Medical writing support was provided by Chrissie Kouremenou of Complete Medical Communications, funded by Almirall S.A.

Disclosures. Gareth J. Thomas has been an advisor and/or speaker for Almirall S.A., Bristol-Myers Squibb, GlaxoSmithKline, and Merck Sharpe \& Dohme. Colin A. Morton has been on advisory boards for AbbVie, Almirall S.A., and Leo Pharma; has been an investigator for Biofrontera AG and Leo Pharma; and has received travel support from Almirall S.A., Galderma, and Leo Pharma.

Compliance with Ethics Guidelines. This article is based on previously conducted studies and does not involve any new studies of human or animal subjects performed by any of the authors. 
Data Availability. Data sharing is not applicable to this article as no data sets were generated or analyzed during the current study.

Open Access. This article is distributed under the terms of the Creative Commons Attribution-NonCommercial 4.0 International License (http://creativecommons.org/licenses/ by-nc/4.0/), which permits any noncommercial use, distribution, and reproduction in any medium, provided you give appropriate credit to the original author(s) and the source, provide a link to the Creative Commons license, and indicate if changes were made.

\section{REFERENCES}

1. Greenhough A, Smartt HJ, Moore AE, et al. The COX-2/PGE2 pathway: key roles in the hallmarks of cancer and adaptation to the tumour microenvironment. Carcinogenesis. 2009;30:377-86.

2. Mikulec CD, Rundhaug JE, Simper MS, Lubet RA, Fischer SM. The chemopreventive efficacies of nonsteroidal anti-inflammatory drugs: the relationship of short-term biomarkers to long-term skin tumor outcome. Cancer Prev Res (Phila). 2013;6:675-85.

3. Kargman SL, O'Neill GP, Vickers PJ, Evans JF, Mancini JA, Jothy S. Expression of prostaglandin $\mathrm{G} / \mathrm{H}$ synthase-1 and -2 protein in human colon cancer. Cancer Res. 1995;55:2556-9.

4. Williams CS, Mann M, DuBois RN. The role of cyclooxygenases in inflammation, cancer, and development. Oncogene. 1999;18:7908-16.

5. Brock TG, McNish RW, Peters-Golden M. Arachidonic acid is preferentially metabolized by cyclooxygenase-2 to prostacyclin and prostaglandin E2. J Biol Chem. 1999;274:11660-6.

6. Rundhaug JE, Fischer SM. Molecular mechanisms of mouse skin tumor promotion. Cancers (Basel). 2010;2:436-82.

7. Zha S, Yegnasubramanian V, Nelson WG, Isaacs WB, De Marzo AM. Cyclooxygenases in cancer: progress and perspective. Cancer Lett. 2004;215:1-20.

8. Fischer SM, Pavone A, Mikulec C, Langenbach R, Rundhaug JE. Cyclooxygenase-2 expression is critical for chronic UV-induced murine skin carcinogenesis. Mol Carcinog. 2007;46:363-71.

9. Mûller-Decker K. Cyclooxygenase-dependent signaling is causally linked to non-melanoma skin carcinogenesis: pharmacological, genetic, and clinical evidence. Cancer Metastasis Rev. 2011;30:343-61.

10. Rundhaug JE, Mikulec C, Pavone A, Fischer SM. A role for cyclooxygenase-2 in ultraviolet light-induced skin carcinogenesis. Mol Carcinog. 2007;46:692-8.

11. Fischer SM, Lo HH, Gordon GB, et al. Chemopreventive activity of celecoxib, a specific cyclooxygenase-2 inhibitor, and indomethacin against ultraviolet light-induced skin carcinogenesis. Mol Carcinog. 1999;25:231-40.

12. Simper MS, Rundhaug JE, Mikulec C, et al. The tumor promoting activity of the EP4 receptor for prostaglandin E2 in murine skin. Mol Oncol. 2014;8:1626-39.

13. Sung YM, He G, Hwang DH, Fischer SM. Overexpression of the prostaglandin E2 receptor EP2 results in enhanced skin tumor development. Oncogene. 2006;25:5507-16.

14. Tober KL, Wilgus TA, Kusewitt DF, Thomas-Ahner JM, Maruyama T, Oberyszyn TM. Importance of the $\mathrm{EP}(1)$ receptor in cutaneous UVB-induced inflammation and tumor development. J Invest Dermatol. 2006;126:205-11.

15. Pentland AP, Schoggins JW, Scott GA, Khan KN, Han R. Reduction of UV-induced skin tumors in hairless mice by selective COX-2 inhibition. Carcinogenesis. 1999;20:1939-44.

16. Buckman SY, Gresham A, Hale P, et al. COX-2 expression is induced by UVB exposure in human skin: implications for the development of skin cancer. Carcinogenesis. 1998;19:723-9.

17. Karagece Yalçin $U$, Seçkin S. The expression of p53 and COX-2 in basal cell carcinoma, squamous cell carcinoma and actinic keratosis cases. Turk Patoloji Derg. 2012;28:119-27.

18. Butler GJ, Neale R, Green AC, Pandeya N, Whiteman DC. Nonsteroidal anti-inflammatory drugs and the risk of actinic keratoses and squamous cell cancers of the skin. J Am Acad Dermatol. 2005;53:966-72.

19. Johannesdottir SA, Chang ET, Mehnert F, Schmidt M, Olesen AB, Sorensen HT. Nonsteroidal anti-inflammatory drugs and the risk of skin cancer: a population-based case-control study. Cancer. 2012;118:4768-76. 
20. Asgari MM, Chren MM, Warton EM, Friedman GD, White E. Association between nonsteroidal anti-inflammatory drug use and cutaneous squamous cell carcinoma. Arch Dermatol. 2010;146:388-95.

21. Grau MV, Baron JA, Langholz B, et al. Effect of NSAIDs on the recurrence of nonmelanoma skin cancer. Int J Cancer. 2006;119:682-6.

22. Muranushi C, Olsen CM, Pandeya N, Green AC. Aspirin and nonsteroidal anti-inflammatory drugs can prevent cutaneous squamous cell carcinoma: a systematic review and meta-analysis. J Invest Dermatol. 2015;135:975-83.

23. Pirard D, Vereecken P, Mélot C, Heenen M. Three percent diclofenac in $2.5 \%$ hyaluronan gel in the treatment of actinic keratoses: a meta-analysis of the recent studies. Arch Dermatol Res. 2005;297:185-9.

24. Fecker LF, Stockfleth E, Braun FK, et al. Enhanced death ligand-induced apoptosis in cutaneous SCC cells by treatment with diclofenac/hyaluronic acid correlates with downregulation of c-FLIP. J Invest Dermatol. 2010;130:2098-109.

25. Nystrom ML, McCulloch D, Weinreb PH, et al. Cyclooxygenase-2 inhibition suppresses alphavbeta6 integrin-dependent oral squamous carcinoma invasion. Cancer Res. 2006;66:10833-42.

26. Shao Y, Li P, Zhu ST, et al. MiR-26a and miR-144 inhibit proliferation and metastasis of esophageal squamous cell cancer by inhibiting cyclooxygenase-2. Oncotarget. 2016;7:15173-86.

27. Kalinski P. Regulation of immune responses by prostaglandin E2. J Immunol. 2012;188:21-8.

28. Liu B, Qu L, Yan S. Cyclooxygenase-2 promotes tumor growth and suppresses tumor immunity. Cancer Cell Int. 2015;15:106.

29. Zelenay S, van der Veen AG, Böttcher JP, et al. Cyclooxygenase-dependent tumor growth through evasion of immunity. Cell. 2015;162:1257-70.

30. Glogau RG. The risk of progression to invasive disease. J Am Acad Dermatol. 2000;42:23-4.

31. Padilla RS, Sebastian S, Jiang Z, Nindl I, Larson R. Gene expression patterns of normal human skin, actinic keratosis, and squamous cell carcinoma: a spectrum of disease progression. Arch Dermatol. 2010;146:288-93.

32. Fernández-Figueras MT, Carrato C, Sáenz X, et al. Actinic keratosis with atypical basal cells (AK I) is the most common lesion associated with invasive squamous cell carcinoma of the skin. J Eur Acad Dermatol Venereol. 2015;29:991-7.

33. Cohen JL. Actinic keratosis treatment as a key component of preventive strategies for nonmelanoma skin cancer. J Clin Aesthet Dermatol. 2010;3:39-44.

34. de Berker D, McGregor JM, Hughes BR. Guidelines for the management of actinic keratoses. $\mathrm{Br} \mathrm{J}$ Dermatol. 2007;156:222-30.

35. Werner RN, Stockfleth E, Connolly SM, et al. Evidenceand consensus-based (S3) Guidelines for the Treatment of Actinic Keratosis-International League of Dermatological Societies in cooperation with the European Dermatology Forum-Short version. J Eur Acad Dermatol Venereol. 2015;29:2069-79.

36. Gupta AK, Paquet M, Villanueva E, Brintnell W. Interventions for actinic keratoses. Cochrane Database Syst Rev. 2012;12:CD004415.

37. Almirall SA. Solareze ${ }^{\mathrm{TM}}$ summary of product characteristics. http://www.medicines.org.uk/ EMC/medicine/21229. Accessed 24 May 2016.

38. Meda Pharmaceuticals. Efudix cream summary of product characteristics. http://www.medicines.org. uk/EMC/medicine/6219. Accessed 27 Dec 2016.

39. Stockfleth E, Kerl H, Zwingers T, Willers C. Low-dose 5-fluorouracil in combination with salicylic acid as a new lesion-directed option to treat topically actinic keratoses: histological and clinical study results. $\mathrm{Br} \mathrm{J}$ Dermatol. 2011;165:1101-8.

40. Almirall Limited. Actikerall $5 \mathrm{mg} / \mathrm{g}+100 \mathrm{mg} / \mathrm{g}$ cutaneous solution summary of product characteristics. http://www.medicines.org.uk/emc/ medicine/24614. Accessed 27 Dec 2016.

41. Stockfleth E, Zwingers T, Willers C. Recurrence rates and patient assessed outcomes of $0.5 \%$ 5 -fluorouracil in combination with salicylic acid treating actinic keratoses. Eur J Dermatol. 2012;22:370-4.

42. Meda Pharmaceuticals. Aldara 5\% cream summary of product characteristics. http://www.medicines. org.uk/EMC/medicine/8. Accessed 27 Dec 2016.

43. EMC. Zyclara $3.75 \%$ cream summary of product characteristics. https://www.medicines.org.uk/emc/ medicine/27323. Accessed 2 Aug 2016.

44. Leo Laboratories Ltd. Picato $150 \mathrm{mcg}$ gel summary of product characteristics. http://www.medicines. org.uk/emc/medicine/27246. Accessed 27 Dec 2016. 
45. Leo Laboratories Ltd. Picato $500 \mathrm{mcg}$ gel summary of product characteristics. http://www.medicines.org. uk/emc/medicine/27247. Accessed 27 Dec 2016.

46. Morton C, Szeimies RM, Sidoroff A, et al. European Dermatology Forum Guidelines on topical photodynamic therapy. Eur J Dermatol. 2015;25:296-311.

47. Dirschka T, Radny $P$, Dominicus $R$, et al. Photodynamic therapy with BF-200 ALA for the treatment of actinic keratosis: results of a multicentre, randomized, observer-blind phase III study in comparison with a registered methyl-5-aminolaevulinate cream and placebo. $\mathrm{Br}$ J Dermatol. 2012;166:137-46.

48. Olsen EA, Abernethy ML, Kulp-Shorten C, et al. A double-blind, vehicle-controlled study evaluating masoprocol cream in the treatment of actinic keratoses on the head and neck. J Am Acad Dermatol. 1991;24:738-43.

49. Dirschka T, Radny P, Dominicus R, et al. Long-term (6 and 12 months) follow-up of two prospective, randomized, controlled phase III trials of photodynamic therapy with BF-200 ALA and methyl aminolaevulinate for the treatment of actinic keratosis. Br J Dermatol. 2013;168:825-36.

50. Lacour JP, Ulrich C, Gilaberte Y, et al. Daylight photodynamic therapy with methyl aminolevulinate cream is effective and nearly painless in treating actinic keratoses: a randomised, investigator-blinded, controlled, phase III study throughout Europe. J Eur Acad Dermatol Venereol. 2015;29:2342-8.

51. Rubel DM, Spelman L, Murrell DF, et al. Daylight photodynamic therapy with methyl aminolevulinate cream as a convenient, similarly effective, nearly painless alternative to conventional photodynamic therapy in actinic keratosis treatment: a randomized controlled trial. Br J Dermatol. 2014;171:1164-71.

52. Dirschka T, Lear JT. Sequential treatment of multiple actinic keratoses with solaraze and actikerall. Case Rep Dermatol. 2014;6:164-8.
53. Berlin JM, Rigel DS. Diclofenac sodium 3\% gel in the treatment of actinic keratoses postcryosurgery. J Drugs Dermatol. 2008;7:669-73.

54. Lembo S, Cantelli M, Francia MG, Lembo C, Balato A, Scalvenzi M. Actinic keratosis: sequential treatment with cryotherapy and 3\% sodium diclofenac gel. Clin Dermatol. 2014;2:11-6.

55. Mastrolonardo M. Topical diclofenac 3\% gel plus cryotherapy for treatment of multiple and recurrent actinic keratoses. Clin Exp Dermatol. 2009;34:33-5.

56. Gilbert DJ. Treatment of actinic keratoses with sequential combination of 5-fluorouracil and photodynamic therapy. J Drugs Dermatol. 2005;4:161-3.

57. Shaffelburg M. Treatment of actinic keratoses with sequential use of photodynamic therapy; and imiquimod 5\% cream. J Drugs Dermatol. 2009;8:35-9.

58. van der Geer S, Krekels GA. Treatment of actinic keratoses on the dorsum of the hands: ALA-PDT versus diclofenac 3\% gel followed by ALA-PDT. A placebo-controlled, double-blind, pilot study. J Dermatol Treat. 2009;20:259-65.

59. Lucena SR, Salazar N, Gracia-Cazaña T, et al. Combined treatments with photodynamic therapy for non-melanoma skin cancer. Int $\mathrm{J}$ Mol Sci. 2015;16:25912-33.

60. Neidecker MV, Davis-Ajami ML, Balkrishnan R, Feldman SR. Pharmacoeconomic considerations in treating actinic keratosis. Pharmacoeconomics. 2009;27:451-64.

61. Primary Care Dermatology Society. Actinic (solar) keratosis-Primary care treatment pathway. http:// www.pcds.org.uk/ee/images/uploads/general/AK_ guidelines_2014_final_aw2.pdf. Accessed 28 Apr 2016. 